\title{
Discrete Improvement in Racial Disparity in Survival among Patients with Stage IV Colorectal Cancer: a 21-Year Population-Based Analysis
}

\author{
A. W. Castleberry • U. Güller • I. Tarantino • \\ M. F. Berry • L. Brügger • R. Warschkow • T. Cerny • \\ C. R. Mantyh • D. Candinas $\cdot$ M. Worni
}

Received: 8 November 2013 / Accepted: 24 March 2014 / Published online: 15 April 2014

(C) 2014 The Society for Surgery of the Alimentary Tract

\begin{abstract}
Purpose Recently, multiple clinical trials have demonstrated improved outcomes in patients with metastatic colorectal cancer. This study investigated if the improved survival is race dependent.

Patients and Methods Overall and cancer-specific survival of 77,490 White and Black patients with metastatic colorectal cancer from the 1988-2008 Surveillance Epidemiology and End Results registry were compared using unadjusted and multivariable adjusted Cox proportional hazard regression as well as competing risk analyses.

Results Median age was 69 years, $47.4 \%$ were female and $86.0 \%$ White. Median survival was 11 months overall, with an overall increase from 8 to 14 months between 1988 and 2008. Overall survival increased from 8 to 14 months for White, and from 6 to 13 months for Black patients. After multivariable adjustment, the following parameters were associated with better survival: White, female, younger, better educated and married patients, patients with higher income and living in urban areas, patients with rectosigmoid junction and rectal cancer, undergoing cancer-directed surgery, having well/moderately differentiated, and N0 tumors ( $p<0.05$ for all covariates). Discrepancies in overall survival based on race did not change significantly over time; however, there was a significant decrease of cancer-specific survival discrepancies over time between White and Black patients with a hazard ratio of 0.995 (95\% confidence interval $0.991-1.000)$ per year $(p=0.03)$.

Conclusion A clinically relevant overall survival increase was found from 1988 to 2008 in this population-based analysis for both White and Black patients with metastatic colorectal cancer. Although both White and Black patients benefitted from this improvement, a slight discrepancy between the two groups remained.
\end{abstract}

A. W. Castleberry $\cdot$ M. F. Berry $\cdot$ C. R. Mantyh $\cdot$ M. Worni $(\bowtie)$

Keywords Metastatic colorectal cancer - Colon cancer ·

Department of Surgery, Duke University Medical Center,

27710 Durham, NC, USA

e-mail: mathias.worni@duke.edu

U. Güller · T. Cerny

Department of Medical Oncology and Hematology,

Cantonal Hospital St. Gallen, 9007 St. Gallen, Switzerland Rectal cancer $\cdot$ Race $\cdot$ Disparity $\cdot$ Ethnicity $\cdot$ Survival

I. Tarantino

Department of General, Visceral and Transplant Surgery, University of Heidelberg, 69120 Heidelberg, Germany

U. Güller $\cdot$ L. Brügger $\cdot$ D. Candinas $\cdot$ M. Worni

Department of Visceral Surgery and Medicine, University of Bern, Inselspital, 3010 Bern, Switzerland

R. Warschkow

Department of Surgery, Cantonal Hospital St. Gallen,

9007 St. Gallen, Switzerland

\section{Introduction}

Approximately $25 \%$ of colorectal cancer (CRC) patients present with metastatic disease while another $25 \%$ develop metastases during their disease course. Considering that colorectal cancer is the third most common malignancy among women and men, metastatic colorectal cancer represents a tremendous public health problem. ${ }^{1}$ Over 140,000 new colorectal cancer diagnoses and over 50,000 colorectal cancer deaths are estimated to occur in 2013 in the USA. ${ }^{1}$ Fortunately, many randomized controlled trials over the past decade have demonstrated improved outcomes in patients with metastatic colorectal cancer. ${ }^{2-4} \mathrm{~A}$ recent population-based report 
demonstrated a significant improvement in survival mainly in young patients in the USA with metastatic colorectal cancer, ${ }^{5}$ indicating that improved outcomes are indeed observed in broader practice outside of the clinical trial setting.

However, racial disparities for CRC are known to exist. Although the CRC-related mortality for Blacks has decreased over the last 20 years, the overall magnitude of this decrease lags behind that observed in White patients, particularly for those presenting with metastatic disease. ${ }^{6}$ Speculation exists that improved CRC outcomes demonstrated in clinical trials have not been fully realized in the Black population due to underutilization of newer CRC chemotherapy regimens, potentially related to a lower frequency of obtaining care from high volume, multidisciplinary centers. ${ }^{7-13}$ Not surprisingly, health care-related disparities affecting minorities such as those seen for CRC have been considered a top priority by the US government. ${ }^{14}$ Whether any progress has been made on a national level in improving these disparities, however, remains unclear. In patients with metastatic colorectal cancer, a paucity of data exists to determine whether racial differences in overall and cancer-specific survival has equalized over time with advances in managing this disease as well as heightened awareness of disparities in care and outcomes. Our objective was therefore to perform a population-based analysis, spanning more than two decades exploring racial survival disparities in patients with metastatic colorectal cancer.

\section{Methods}

Data on colorectal cancer patients were extracted from 1988 to 2008 from the US population-based Surveillance, Epidemiology, and End Results (SEER) registry. ${ }^{15}$ SEER is the largest US validated cancer registry and is sponsored by the National Cancer Institute. This registry captures a vast amount of data on approximately $28 \%$ of cancer cases in the USA, including patient characteristics, treatment (surgery and radiotherapy), and survival information. Trained personnel systematically collect information including patient characteristics, data on tumor stage, tumor grading, overall survival (OS), cancerspecific survival (CSS), and information regarding tumordirected surgery (e.g., removal of the primary tumor). However, data on comorbidities and chemotherapy cannot be ascertained based on the SEER data.

SEER*Stat 7.0.5 was used to extract patients with metastatic colorectal adenocarcinoma. The "SEER Site Recode" variable was used to preliminary identify patients with a tumor of the "colon," the "rectosigmoid junction," and the "rectum"; further, the "Histologic Type ICD-O-3" (International Classification of Diseases for Oncology, third edition) variable was used to limit the colorectal tumors to adenocarcinoma. ${ }^{16}$

Patients diagnosed with metastatic colorectal adenocarcinoma from January 1, 1988 through December 31, 2008 aged
18 years and older were included. Patients diagnosed after 2008 were excluded to ensure sufficient follow-up time to adequately evaluate survival outcomes. To explore racial disparities among White and Black patients, the dataset was limited to those two patient groups. Patients with metastatic disease were identified through the variable "Extent of Disease" with the code 85 (metastatic disease) for years 19882003 and the variable "Derived AJCC M 6th edition 2004" for years 2004-2008 with M1 disease. Patients in whom the tumor was diagnosed at autopsy or if it was first cited on the death certificate were excluded from the study. The primary outcome of interest was overall survival measured in months. Secondary outcome was cancer-specific survival. Patients who were still alive at the last reported date were rightcensored in the survival analysis. The primary predictor in the analysis was year of diagnosis. To assess additional patient specific predictors of overall and cancer-specific survival, the following patient characteristics were extracted: age, gender, marital status (married, other/unknown), tumor location (colon, rectosigmoid junction, rectal), stage of nodal disease (N0, $\mathrm{N}+$, NX), tumor grade (well/moderately differentiated, poor/undifferentiated, unknown), cancer-directed surgery, location (rural, urban $\leq 250,000$, urban $\geq 250,000$ habitants), percentage of education below high school (per ZIP code, grouped in tertiles), and median family income per ZIP code (grouped in tertiles). As information on T-stage was not available before 2004, we did not include this information in our analysis.

\section{Statistical Analysis and Outcomes}

Demographical data and tumor characteristics are presented as mean (standard deviation, SD) and median (interquartile range, IQR) for continuous and counts (percentage) for categorical variables. Overall survival was first analyzed using the Kaplan-Meier approach with survival curves compared using the log-rank test. Kaplan-Meier curves for 5-year overall and cancer-specific survival were drawn after right censoring of patients who survived longer than 5 years. Second, unadjusted and multivariable adjusted Cox proportional hazard regression analyses were performed to assess cumulative risk of death among White and Black patients. The following covariates were incorporated into the survival model: age (continuous variable), gender, marital status, tumor location, N-stage, tumor grade, cancer directed surgery, rural/urban location, education below high school, and median family income. To evaluate the trend in survival over time, we included year as a predictor variable in unadjusted and adjusted Cox proportional hazard models and quantified the related hazard ratio from 1988 to 2008 . To identify whether or not discrepancies in racial survival changed over time, an interaction term between race and year of cancer diagnosis was added to the model. It 
was a priori decided to keep only significant interaction terms in the final model. All estimates are presented as hazard ratios (HR) and related $95 \%$ confidence intervals (CI). Similar analyses were repeated for CSS; however, hazard ratios were calculated according to competing-risk regression models described by Fine and Gray accounting for the fact that cancerspecific death prevents the occurrence of non-cancer-specific death. ${ }^{17}$

To further elucidate potential racial disparities irrespective of income, education, or urban/rural location, we performed subgroup analyses for the following populations: (1) the tertile with the lowest median family income; (2) the tertile with the lowest education (based on the rate of high school completion); and (3) patients living in urban areas with $>250,000$ inhabitants. We additionally performed subgroup analyses for patients aged 65 years or younger.

The $p$ values for all analyses were calculated two-sided while the significance level alpha was set at 0.05 . All analyses were performed using STATA 11.2/SE (Stata Corporation, College Station, TX), with visual graphics compiled using Microsoft Excel (Microsoft Corporation, Redmond, WA) or JMP Pro Version 9.0.0 (SAS Institute Inc., Cary, NC).

\section{Results}

In total, 77,490 of 539,274 (14.4\%) colorectal cancer patients in SEER met the inclusion criteria with histologically proven metastatic colorectal adenocarcinoma (Fig. 1). The majority of the patients were White $(n=66,668,86.0 \%)$ (Table 1). Median age was 69 years (IQR 58-78), 58.4\% of all patients were older than 65 years of age, and $47.4 \%(n=36,723)$ were female. The localization of the primary tumor was in the colon, at the rectosigmoid junction, and in the rectum in $75.4,9.2$, and $15.4 \%$ of all patients, respectively. Overall, $66.0 \%$ of patients underwent cancer-directed surgery (i.e., removal of the primary cancer). More Black patients (75.1\%) lived in urban areas with a population $>250,000$ than White patients (59.8\%). Demographically, Black patients resided in an area with a higher percentage of people with education below high school level compared to White patients, while the median family income per ZIP code was higher for White $(\$ 49,818)$ than for Black patients $(\$ 47,689)$. Black patients (mean $=64.2$ years, SD 13.4) were younger than White patients (67.9 years, SD 13.4) and less often married (39.6 vs. $55.7 \%)$.

\section{Overall Survival}

For all patients in the study population combined, median OS was 11 months (CI, 11-11), which increased from 8 months (CI, 7-9) in 1988 to 14 months (CI, 13-15) in 2008 (Fig. 2). Median CSS was 13 months (CI, 13-13) with an increase
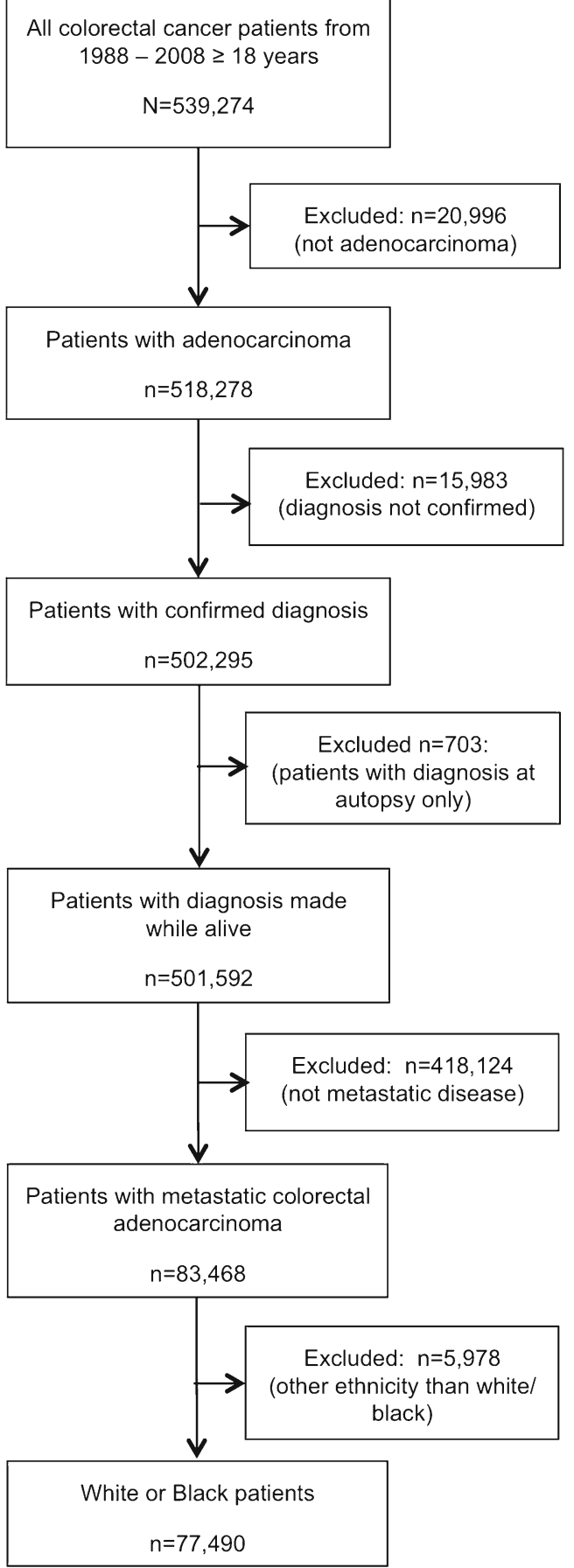

Fig. 1 Flow chart of patient cohort definition

from 10 months (CI, 9-10) in 1988 to 18 months (CI, 16-18) in 2008. Median OS for White patients was 11 months (CI, 11-11) and 10 months (CI, 10-10) for Black patients. In White patients, median OS increased from 8 months (CI, 89) in 1988 to 14 months (CI, 14-15) in 2008 compared to 6 months (CI, 5-9) in 1988 and 13 months (CI, 11-14) in 2008 for Black patients (Fig. 3). Survival curves significantly differed $(p<0.001)$ between White and Black patients for OS (Fig. 4). 
Table 1 Patient demographics

\begin{tabular}{|c|c|c|c|c|}
\hline & $\begin{array}{l}\text { Overall } \\
(n=77,490)\end{array}$ & $\begin{array}{l}\text { White } \\
(n=66,668)\end{array}$ & $\begin{array}{l}\text { Black } \\
(n=10,822)\end{array}$ & $p$ value \\
\hline \multicolumn{5}{|l|}{ Gender } \\
\hline Male & 40,767 (52.6) & $35,387(53.1)$ & $5,380(49.7)$ & \multirow[t]{2}{*}{$<0.001$} \\
\hline Female & $36,723(47.4)$ & $31,281(46.9)$ & $5,442(50.3)$ & \\
\hline \multicolumn{5}{|l|}{ Age } \\
\hline Mean SD & $67,4(13.5)$ & $67.9(13.4)$ & $64.2(13.4)$ & \multirow[t]{2}{*}{$<0.001$} \\
\hline Median IQR & $69(58-78)$ & $69(59-78)$ & $65(55-74)$ & \\
\hline$\leq 65$ years & 32,239 (41.6) & $26,549(39.8)$ & $5,690(52.6)$ & \multirow[t]{2}{*}{$<0.001$} \\
\hline$>65$ years & $45,251(58.4)$ & $40,119(60.2)$ & $5,132(4.4)$ & \\
\hline \multicolumn{5}{|l|}{ Marital status } \\
\hline Married & $41,388(53.4)$ & $37,099(55.7)$ & 4,289 (39.6) & \multirow[t]{2}{*}{$<0.001$} \\
\hline Other/unknown & $36,102(46.6)$ & $29,569(44.3)$ & $6,533(60.4)$ & \\
\hline \multicolumn{5}{|l|}{ Tumor location } \\
\hline Colon & $58,430(75.4)$ & $49,699(74.5)$ & $8,731(80.7)$ & \multirow[t]{3}{*}{$<0.001$} \\
\hline Rectosigmoid junction & $7,091(9.2)$ & $6,265(9.4)$ & $826(7.6)$ & \\
\hline Rectum & $11,969(15.4)$ & $10,704(16.1)$ & $1,265(11.7)$ & \\
\hline \multicolumn{5}{|l|}{ N-stage } \\
\hline No & $16,474(21.3)$ & $13,864(20.8)$ & $2,610(24.1)$ & \multirow[t]{3}{*}{$<0.001$} \\
\hline $\mathrm{N}+$ & $43.182(55.7)$ & $37,519(56.3)$ & $5,663(52.3)$ & \\
\hline NX & $17,834(23.0)$ & 15,285 (22.9) & $2,549(23.6)$ & \\
\hline \multicolumn{5}{|l|}{ Tumor grade } \\
\hline Well/moderately differentiated & $43,542(56.2)$ & $37,030(55.5)$ & $6,512(60.2)$ & \multirow[t]{3}{*}{$<0.001$} \\
\hline Poor/undifferentiated & $20,639(26.6)$ & $18,398(27.6)$ & $2,241(20.7)$ & \\
\hline Unknown & $13,309(17.2)$ & $11,240(16.9)$ & $2,069(19.1)$ & \\
\hline \multicolumn{5}{|l|}{ Cancer-directed surgery } \\
\hline No & $24,206(31.2)$ & $20,406(30.6)$ & $3,800(35.1)$ & \multirow[t]{3}{*}{$<0.001$} \\
\hline Yes & $51,142(66.0)$ & $44,441(66.7)$ & $6,701(61.9)$ & \\
\hline Unknown & $2,142(2.8)$ & $1,821(2.7)$ & $321(3.0)$ & \\
\hline \multicolumn{5}{|l|}{ Rural/urban } \\
\hline Rural & $1,315(1.7)$ & $1,238(1.9)$ & $77(0.7)$ & \multirow[t]{4}{*}{$<0.001$} \\
\hline Urban $\leq 250,000$ & $28,166(36.4)$ & $25,544(38.3)$ & $2,622(24.2)$ & \\
\hline Urban $>250,000$ & $48,006(61.9)$ & $39,883(59.8)$ & $8,123(75.1)$ & \\
\hline Unknown & $3(0)$ & $3(0)$ & 0 & \\
\hline $\begin{array}{l}\text { Education below high school (\%) } \\
\text { (mean, SD) }\end{array}$ & $21.0(7.3)$ & $20.6(7.3)$ & $23.1(6.8)$ & $<0.001$ \\
\hline Group $1(3.67-16.75)$ & $25,579(33.0)$ & $23,163(34.7)$ & $2,416(22.3)$ & \multirow[t]{4}{*}{$<0.001$} \\
\hline Group $2(16.77-22.96)$ & $24,213(31.3)$ & $21.305(32.0)$ & $2,908(26.9)$ & \\
\hline Group 3 (23.02-57.23) & $27,695(35,7)$ & $22,197(33.3)$ & $5,498(50.8)$ & \\
\hline Unknown & $3(0)$ & $3(0)$ & 0 & \\
\hline $\begin{array}{l}\text { Median family income per ZIP } \\
\text { code (mean, SD) }\end{array}$ & $49,521(13,352)$ & $49,818(13,569)$ & $47,689(11,758)$ & $<0.001$ \\
\hline Group $1(\$ 15,510-\$ 44,040)$ & $25,602(33.0)$ & $21,569(32.4)$ & $4,033(37,3)$ & $<0.001$ \\
\hline Group $2(\$ 44,050-\$ 53,370)$ & $25,933(33.5)$ & $22,130(33.2)$ & $3,803(35.1)$ & \\
\hline Group $3(\$ 53,430-\$ 91,050)$ & $25,952(33.5)$ & $22,966(34.4)$ & $2,986(27.6)$ & \\
\hline Unknown & $3(0)$ & $3(0)$ & 0 & \\
\hline \multicolumn{5}{|l|}{ Cause of death } \\
\hline Colorectal cancer & $59,971(77.4)$ & $51.654(77.5)$ & 8,317 (76.9) & \multirow[t]{3}{*}{$<0.001$} \\
\hline Other & $10,400(13.4)$ & $8,815(13.2)$ & $1,585(14.6)$ & \\
\hline Alive & $7,119(9.2)$ & $6,199(9.3)$ & $920(8.5)$ & \\
\hline \multicolumn{5}{|l|}{ Year } \\
\hline $1988-1995$ & $17,452(22.5)$ & $15,431(23.2)$ & $2,021(18.7)$ & $<0.001$ \\
\hline 1996-2002 & $26,486(34.2)$ & $22,773(34.2)$ & $3,713(34.3)$ & \\
\hline $2003-2008$ & $33,552(43.3)$ & $28,464(42.7)$ & $5,088(47.0)$ & \\
\hline
\end{tabular}

All values are given as count and percent if not otherwise specified $I Q R$ interquartile range 


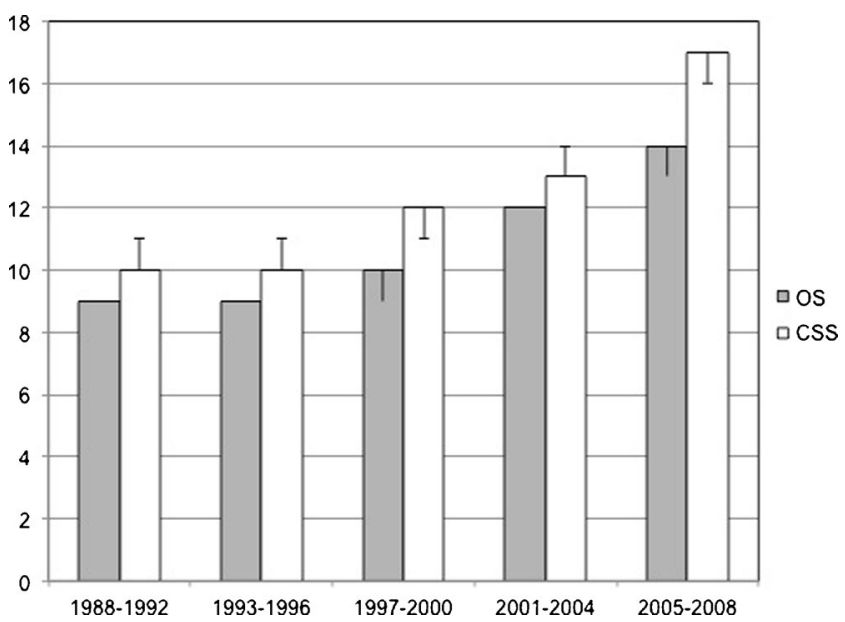

Fig. 2 Trend of median overall and cancer-specific survival from 1988 to 2008. OS overall survival, CSS cancer-specific survival, $x$-axis time period (year), y-axis median survival in months, error bars $95 \%$ confidence interval

In unadjusted Cox proportional hazard regression analyses for OS, cumulative risk of all-cause mortality was higher for Blacks compared to Whites (HR, 1.08; CI, 1.06-1.11; $p<0.001$ ) (Table 2). For the combined study population (White and Black), OS significantly improved per 1-year increment (HR, 0.979; CI, 0.977-0.980; $p<0.001$ ). However, the interaction term between race and year was not significant, indicating the survival discrepancy between Whites and Blacks did not change over time.

For all patients, improved OS per 1-year increment retained statistical significance upon multivariable adjusted analysis (adjusted HR [aHR], 0.976; CI, 0.975-0.978; $p<0.001$ ). Proportional hazard for all-cause mortality persisted to be higher for Blacks compared to Whites (aHR, 1.13; CI, 1.11-1.16; $p<0.001$ ). Similar to the unadjusted analysis, the discrepancy in survival between Whites and Blacks did not change over time as indicated by lack of significance for the interaction

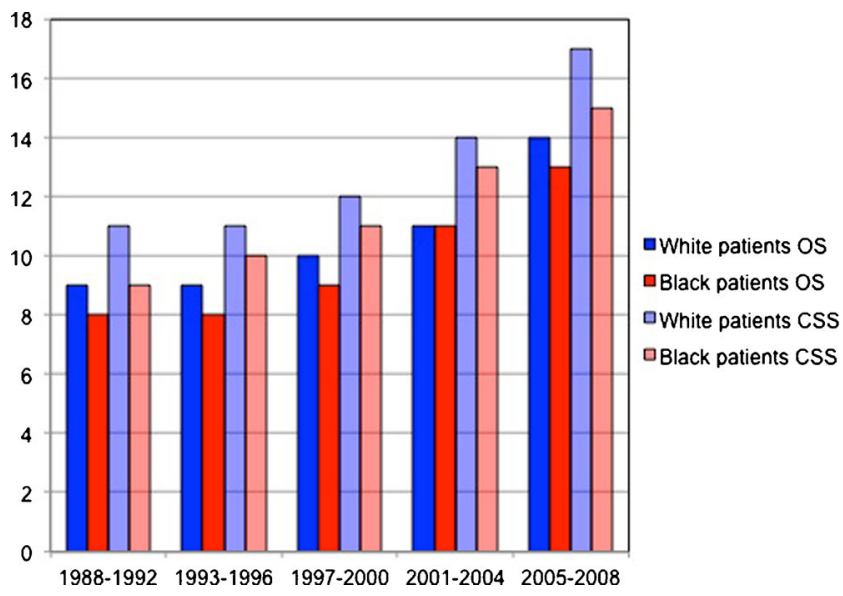

Fig. 3 Trend analysis of median overall $(O S)$ and cancer-specific survival (CSS) from 1988 to 2008 for White and Black patients with metastatic colorectal cancer patients. $x$-axis time period (year), $y$-axis median survival in months. OS overall survival, CSS cancer-specific survival term (aHR, 0.998; CI, 0.994-1.002; $p=0.26$ ). Focusing the analysis to the most recent years of the study (2006 to 2008), the adjusted HR for race was 1.12 (CI, $1.06-1.17 ; p<0.001$ ), again demonstrating higher mortality risk for Blacks compared to Whites.

In multivariable adjusted analyses, the risk of dying (OS) was lower compared to their counterparts for the following patient groups: females, married and younger patients, tumor locations in the rectosigmoid junction or in the rectum, well/moderately differentiated tumors, patients with cancerdirected surgery, patients living in urban regions and having a higher education level, and a median family income of over $\$ 53,430$.

\section{Cancer-Specific Survival}

Results for CSS based on multivariable adjusted competing risk analyses showed worse survival for Blacks compared to Whites for year 1988 (aHR, 1.19; CI, 1.12-1.26; $p<0.001$ ) and improved survival per 1-year increment over time (aHR, 0.959; CI, 0.957-0.961; $p<0.001)$. Per 1-year increment, there was a significant reduction of the difference in CSS between Whites and Blacks (aHR for race/year interaction term, 0.995; CI, 0.991-1.000; $p=0.03$ ) (Table 3). However, limiting the analyses to patients from 2006 to 2008, the adjusted HR (aHR, 1.10; CI, 1.04-1.17; $p=0.001$ ) continued to demonstrate higher cancer-specific risk of death for Blacks compared to Whites. Most of the other characteristics showed similar results; however, no difference was found for gender and median family income per ZIP code.

\section{Subgroup Analyses}

Multivariable adjusted subgroup analyses were performed for four subgroups. For patients within the lowest income tertile, results for OS and CSS showed that Blacks had worse survival than Whites (aHR, 1.12; CI, 1.08-1.16, $p<0.001$; aHR, 1.11; CI, 1.06-1.16, $p<0.001$, respectively), improved OS and CSS per 1-year increment over time for the whole study population (White and Black) (aHR, 0.978; CI, 0.976-0.981, $p<0.001$; aHR, 0.963; CI, 0.960-0.967, $p<0.001$, respectively), while there was no significant change in the discrepancy between Blacks and Whites over time in OS and CSS (aHR interaction term race $\times$ year, $0.995 ; \mathrm{CI}, 0.989-1.001, p=0.12$; aHR, 0.994; CI, 0.987-1.001, $p=0.09$, respectively). For patients within the highest tertile for education level below high school provided the following results: Blacks had worse OS and CSS compared to Whites (aHR, 1.15; CI, 1.11-1.18, $p<0.001$; aHR, 1.14; CI, 1.10-1.18, $p<0.001$, respectively), while OS and CSS improved significantly per 1-year increment (aHR, 0.975; CI, 0.972-0.978, $p<0.001$; aHR, 0.955; CI, 0.952$0.958, p<0.001$, respectively). There was no significant change in the survival discrepancy for OS and CSS between 
Fig. 4 Five-year survival curves for overall and cancer-specific survival stratified by race (White vs. Black) for years 1988 to 2008

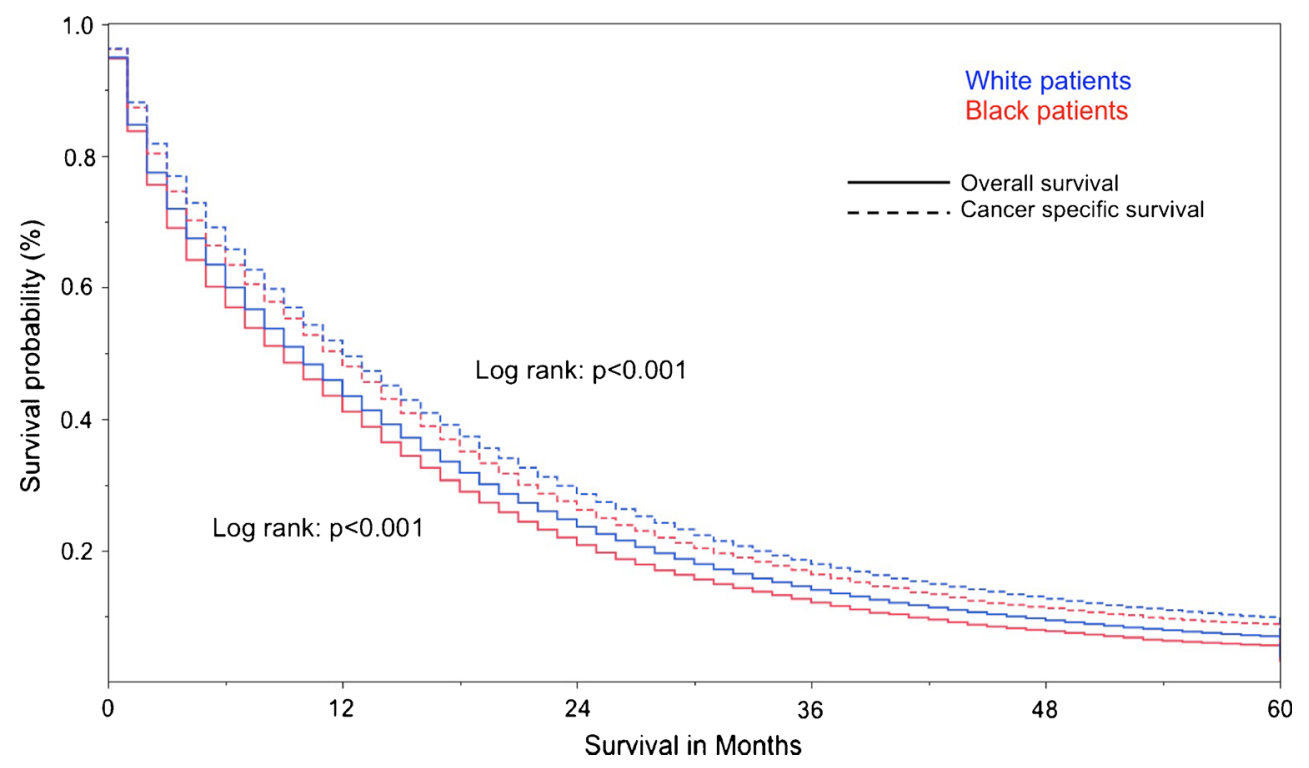

Whites and Blacks over this time period (aHR interaction term race $\times$ year, 0.998; CI, 0.992-1.004, $p=0.46$; aHR, 0.997; CI, $0.991-1.004, p=0.41$, respectively). Among patients residing in urban areas with more than 250,000 inhabitants, Blacks have worse OS and CSS compared to Whites (aHR, 1.14; CI, $1.11-1.17, p<0.001$; aHR, 1.14; CI, 1.11-1.17, $p<0.001$, respectively) while OS and CSS significantly improved over time per 1-year increment (aHR, 0.975; CI, 0.973-0.978, $p<0.001$; aHR, 0.957; CI, 0.955-0.959, $p<0.001)$. No changes were found for the discrepancy in OS and CSS between Whites and Blacks (aHR interaction term race $\times$ year, 1.000; CI, 0.996-1.005, $p=0.93$; aHR, 0.998; CI, 0.993-1.003, $p=$ 0.43 , respectively). Among patients aged 65 years and younger, the adjusted HR of the interaction term between race and year was not significant for OS (aHR, 1.000; CI, 0.994-1.005, $p=0.912$ ) and for CSS (aHR, 0.999; CI, 0.993-1.005, $p=$ $0.665)$.

\section{Discussion}

The present analysis provides compelling evidence that overall and cancer-specific survival have significantly improved over the past two decades for both Black and White patients; however, a significant racial survival discrepancy persists. While improvement in this discrepancy over time was observed for cancer-specific survival, the results were less encouraging for overall survival. By subgroup analysis, these findings were confirmed among poor patients, poorly educated patients, and among patients living in urban areas with $>250,000$ inhabitants.

The improvements in outcomes for patients with metastatic colorectal cancer are likely due to a variety of factors. First, surgical treatment for metastatic colorectal cancer has changed over the past few decades. Indeed, more aggressive strategies are performed for liver metastases, ${ }^{18}$ including portal vein embolization to increase the liver remnant prior to resection, two- and three-step procedures to clear the liver from metastases, ${ }^{19}$ alternative methods such as radiofrequency ablation to destroy metastases that cannot be resected, ${ }^{20}$ as well as more aggressive surgical resection of lung metastases. ${ }^{21}$ Second, new, potentially beneficial strategies in the treatment of metastatic colorectal cancer have been developed in recent years. While a decade ago it was standard to resect the primary tumor first, the so-called liver-first reversed management is now often successfully used. ${ }^{22}$ Third, major advances have been made in systemic treatment. Indeed, 10 years ago, only two chemotherapeutic drugs (5-fluoropyrimidine and irinotecan) were available for the treatment of metastatic colorectal cancer, while the number of agents in the armamentarium has significantly increased over the past decade. In addition to more chemotherapeutic drugs such as oxaliplatin, ${ }^{2}$ there are also antibodies that now play an important role in the treatment of metastatic colorectal cancer. Both anti-VEGF antibodies $^{4}$ as well as anti-EGFR-antibodies ${ }^{3,23}$ have shown to improve outcomes in patients with metastatic colorectal cancer. Moreover, new small molecules such as oral multikinase inhibitors (e.g., Regorafenib) ${ }^{24}$ and so-called VEGF-trap fusion proteins (e.g., Aflibercept) ${ }^{25}$ are successfully being used. Finally, new concepts have developed such as continuing certain agents beyond progression. This has been demonstrated in a recently published phase III trial, in which bevacizumab was continued even if patients progressed during first-line treatment. ${ }^{26}$ However, for the vast majority of metastatic colorectal cancer patients treated from 1998 to 2008 in the present analysis, many of these newer agents (e.g., anti-VEGF or anti-EGFR antibodies, oral multikinase inhibitors, VEGF trap) were not yet available. Therefore, it 
Table 2 Unadjusted and multivariable adjusted analyses of overall survival
Ref. reference group, $N A$ not applicable, interaction term race $\mathrm{X}$ year not included in multivariable adjusted analysis

\begin{tabular}{|c|c|c|c|c|}
\hline & $\begin{array}{l}\text { Unadjusted hazard } \\
\text { ratio }(95 \% \mathrm{CI})\end{array}$ & $p$ value & $\begin{array}{l}\text { Adjusted hazard } \\
\text { ratio }(95 \% \mathrm{CI})\end{array}$ & $p$ value \\
\hline \multicolumn{5}{|l|}{ Race } \\
\hline White & Ref. & & Ref. & \\
\hline Black & $1.08(1.06-1.11)$ & $<0.001$ & $1.13(1.11-1.16)$ & $<0.001$ \\
\hline Year (continuous) & $0.979(0.977-0.980)$ & $<0.001$ & $0.976(0.975-0.978)$ & $<0.001$ \\
\hline Race $\times$ year interaction & $1.000(0.996-1.004)$ & 0.85 & $0.998(0.994-1.002)$ & 0.26 \\
\hline \multicolumn{5}{|l|}{ Age } \\
\hline $\begin{array}{l}\text { Continuous } \\
\leq 65 \text { years }\end{array}$ & $\begin{array}{l}1.021(1.020-1.022) \\
\text { Ref. }\end{array}$ & $<0.001$ & $1.019(1.019-1.020)$ & $<0.001$ \\
\hline$>65$ years & $1.55(1.52-1.57)$ & $<0.001$ & NA & \\
\hline \multicolumn{5}{|l|}{ Gender } \\
\hline Male & Ref. & & Ref. & \\
\hline Female & $1.03(1.02-1.05)$ & $<0.001$ & $0.97(0.95-0.98)$ & $<0.001$ \\
\hline \multicolumn{5}{|l|}{ Marital status } \\
\hline Married & $0.80(0.79-0.81)$ & $<0.001$ & $0.86(0.85-0.88)$ & \\
\hline Unmarried & Ref. & & Ref. & $<0.001$ \\
\hline \multicolumn{5}{|l|}{ Tumor location } \\
\hline Colon & Ref. & & Ref. & $<0.001$ \\
\hline Rectosigmoid junction & $0.83(0.81-0.85)$ & $<0.001$ & $0.84(0.82-0.87)$ & $<0.001$ \\
\hline Rectal & $0.87(0.86-0.89)$ & & $0.75(0.74-0.77)$ & $<0.001$ \\
\hline \multicolumn{5}{|l|}{$\mathrm{N}$-stage } \\
\hline No & Ref. & & Ref. & \\
\hline $\mathrm{N}+$ & $1.14(1.12-1.16)$ & $<0.001$ & $1.36(1.33-1.39)$ & $<0.001$ \\
\hline NX & $2.04(1.99-2.08)$ & $<0.001$ & $1.29(1.26-1.33)$ & $<0.001$ \\
\hline \multicolumn{5}{|l|}{ Tumor grade } \\
\hline Well/moderately differentiated & Ref. & & Ref. & \\
\hline Poor/undifferentiated & $1.40(1.37-1.42)$ & $<0.001$ & $1.42(1.40-1.45)$ & $<0.001$ \\
\hline Unknown & $1.68(1.65-1.72)$ & $<0.001$ & $1.14(1.11-1.17)$ & $<0.001$ \\
\hline \multicolumn{5}{|l|}{ Cancer-directed surgery performed } \\
\hline No & Ref. & & Ref. & \\
\hline Yes & $0.49(0.48-0.50)$ & $<0.001$ & $0.43(0.42-0.44)$ & $<0.001$ \\
\hline Other/unknown & $0.56(0.54-0.59)$ & $<0.001$ & $0.57(0.55-0.60)$ & $<0.001$ \\
\hline \multicolumn{5}{|l|}{ Rural/urban } \\
\hline Rural & Ref. & & Ref. & \\
\hline Urban $\leq 250,000$ & $0.92(0.87-0.98)$ & 0.008 & $0.94(0.89-1.00)$ & 0.04 \\
\hline Urban $>250,000$ & $0.92(0.87-0.98)$ & 0.008 & $0.93(0.87-0.99)$ & 0.02 \\
\hline \multicolumn{5}{|l|}{ Education below high school (\%) } \\
\hline Group 1 (3.67-16.75) & Ref. & & Ref. & \\
\hline Group 2 (16.77-22.96) & $1.08(1.06-1.10)$ & $<0.001$ & $1.03(1.01-1.05)$ & 0.004 \\
\hline Group 3 (23.02-57.23) & $1.09(1.07-1.11)$ & $<0.001$ & $1.05(1.02-1.07)$ & $<0.001$ \\
\hline \multicolumn{5}{|l|}{ Median family income per ZIP code } \\
\hline Group $1(\$ 15,510-\$ 44,040)$ & Ref. & & Ref. & \\
\hline Group $2(\$ 44,050-\$ 53,370)$ & $0.93(0.92-0.95)$ & $<0.001$ & $0.99(0.97-1.01)$ & 0.28 \\
\hline Group $3(\$ 53,430-\$ 91,050)$ & $0.84(0.83-0.86)$ & $<0.001$ & $0.94(0.92-0.97)$ & $<0.001$ \\
\hline
\end{tabular}

remains to be seen in future analyses whether the rapid increase in drugs in the armamentarium of metastatic colorectal cancer patients will further improve outcomes on a population-based level.
While it is encouraging that the discussed improvements have significantly impacted overall and cancer-specific survival of both White and Black patients, the survival discrepancy between those two groups only decreased for cancer 
Table 3 Unadjusted and multivariable adjusted analyses of cancer-specific survival (competing risk analyses)
Ref. reference group, $N A$ not applicable, \# for year 1988

\begin{tabular}{|c|c|c|c|c|}
\hline & $\begin{array}{l}\text { Unadjusted hazard } \\
\text { ratio }(95 \% \mathrm{CI})\end{array}$ & $p$ value & $\begin{array}{l}\text { Adjusted hazard } \\
\text { ratio }(95 \% \mathrm{CI})\end{array}$ & $p$ value \\
\hline \multicolumn{5}{|l|}{ Race } \\
\hline White & Ref. & & Ref. & \\
\hline Black & $1.05(1.03-1.08)$ & $<0.001$ & 1.19 (1.12-1.26)\# & $<0.001$ \\
\hline Year (continuous) & $0.963(0.962-0.964)$ & $<0.001$ & $0.959(0.957-0.961)$ & $<0.001$ \\
\hline Race $\times$ year interaction & $0.998(0.993-1.002)$ & 0.25 & $0.995(0.991-1.000)$ & 0.03 \\
\hline \multicolumn{5}{|l|}{ Age } \\
\hline Continuous & $1.018(1.017-1.019)$ & $<0.001$ & $1.016(1.015-1.017)$ & $<0.001$ \\
\hline$\leq 65$ years & Ref. & & NA & \\
\hline$>65$ years & $1.47(1.45-1.50)$ & $<0.001$ & & \\
\hline \multicolumn{5}{|l|}{ Gender } \\
\hline Male & Ref. & & Ref. & \\
\hline Female & $1.05(1.03-1.07)$ & $<0.001$ & $0.99(0.97-1.01)$ & 0.27 \\
\hline \multicolumn{5}{|l|}{ Marital status } \\
\hline Married & $0.83(0.82-0.85)$ & $<0.001$ & $0.88(0.87-0.90)$ & \\
\hline Unmarried & Ref. & & Ref. & $<0.001$ \\
\hline \multicolumn{5}{|l|}{ Tumor location } \\
\hline Colon & Ref. & & Ref. & \\
\hline Rectosigmoid junction & $0.84(0.82-0.87)$ & $<0.001$ & $0.85(0.82-0.87)$ & $<0.001$ \\
\hline Rectal & $0.87(0.85-0.89)$ & $<0.001$ & $0.76(0.75-0.78)$ & $<0.001$ \\
\hline \multicolumn{5}{|l|}{$\mathrm{N}$-stage } \\
\hline No & Ref. & & Ref. & $<0.001$ \\
\hline $\mathrm{N}+$ & $1.21(1.18-1.23)$ & $<0.001$ & $1.41(1.38-1.44)$ & $<0.001$ \\
\hline NX & $2.03(1.98-2.09)$ & $<0.001$ & $1.32(1.28-1.36)$ & \\
\hline \multicolumn{5}{|l|}{ Tumor grade } \\
\hline Well/moderately differentiated & Ref. & & Ref. & \\
\hline Poor/undifferentiated & $1.41(1.38-1.44)$ & $<0.001$ & $1.43(1.40-1.46)$ & $<0.001$ \\
\hline Unknown & $1.54(1.50-1.57)$ & $<0.001$ & $1.07(1.04-1.10)$ & $<0.001$ \\
\hline \multicolumn{5}{|l|}{ Cancer-directed surgery performed } \\
\hline No & Ref. & & Ref. & \\
\hline Yes & $0.54(0.53-0.56)$ & $<0.001$ & $0.45(0.43-0.46)$ & $<0.001$ \\
\hline Other/unknown & $0.56(0.53-0.60)$ & $<0.001$ & $0.57(0.54-0.60)$ & $<0.001$ \\
\hline \multicolumn{5}{|l|}{ Rural/urban } \\
\hline Rural & Ref. & & Ref. & \\
\hline Urban $\leq 250,000$ & $0.94(0.88-1.00)$ & 0.04 & $0.95(0.89-1.01)$ & 0.09 \\
\hline Urban $>250,000$ & $0.93(0.88-0.99)$ & 0.03 & $0.91(0.85-0.97)$ & 0.004 \\
\hline \multicolumn{5}{|l|}{ Education below high school (\%) } \\
\hline Group 1 (3.67-16.75) & Ref. & & Ref. & \\
\hline Group 2 (16.77-22.96) & $1.08(1.06-1.10)$ & $<0.001$ & $1.01(0.99-1.03)$ & 0.38 \\
\hline Group 3 (23.02-57.23) & $1.06(1.04-1.08)$ & $<0.001$ & $1.04(1.02-1.07)$ & $<0.001$ \\
\hline \multicolumn{5}{|l|}{ Median family income per ZIP code } \\
\hline Group $1(\$ 15,510-\$ 44,040)$ & Ref. & & Ref. & \\
\hline Group $2(\$ 44,050-\$ 53,370)$ & $0.90(0.88-0.92)$ & $<0.001$ & $1.02(1.00-1.05)$ & 0.06 \\
\hline Group $3(\$ 53,430-\$ 91,050)$ & $0.80(0.78-0.81)$ & $<0.001$ & $1.00(0.97-1.03)$ & 0.92 \\
\hline
\end{tabular}

specific, but not for overall survival, over the last two decades. The reason for such persistent racial differences is not well understood. One factor that might contribute to worse overall and cancer-specific survival in the Black population with metastatic colorectal cancer is that this population commonly presents with more advanced disease at the time of cancer detection. ${ }^{7}$ Among all colorectal cancer patients recorded in SEER from 2000 to $2010,18.3 \%$ of Whites and $22.9 \%$ of 
Blacks had distant disease at the time of diagnosis. ${ }^{15}$ Although Black patients undergoing colorectal cancer screening have significantly increased, there is still a lag compared to White patients. ${ }^{27-29}$ Also, it has been demonstrated that Black patients are prone to underutilize newer, more effective treatments in general and newer chemotherapy drugs for metastatic colorectal cancer disease specifically. ${ }^{8-10}$ Beside differences in access to care, Blacks have been shown to have a higher degree of distrust in the health care system. ${ }^{30,31}$ It is also suggested that patient-related factors existing prior to the detection of metastatic colorectal cancer might be influential for their outcome including comorbidities, diet, and physical activity. ${ }^{32-34}$ Additionally, it has been shown that Black patients are less often treated in high volume and quality hospitals, which has been associated with lower insurance status. ${ }^{7,11-13}$ Our results support those findings to some extent as patients with better education and higher incomes have better OS compared to their counterparts. A report of Laiyemo et al. highlights the importance of the differences in health care utilization by race as its impact seems to exceed the differences in tumor biology in explaining long-term outcomes among colorectal cancer patients. ${ }^{35}$ Robbins et al. recently reported that mortality rates overall for colorectal cancer significantly decreased from 1985 to 2008 , while major Black-White disparities persist especially for advanced stage disease. ${ }^{6}$ Against the governmental aim of decreasing racial disparity in the USA, they also reported that the differences in mortality rates among Black and White patients with distantstage disease did indeed increase. Given the results of our analysis, we were unable to support this finding while focusing on survival time rather than survival rates. While SEER is an excellent dataset to describe population-based trends in outcomes of patients with metastatic colorectal cancer, it is not possible to further assess detailed reasons for the differential outcomes between race.

As a result of the multivariable analysis, it is notable that patients with metastatic colon cancer have a significantly worse prognosis compared to patients with rectal cancer. There are different explanations for this interesting phenomenon: first, more treatment modalities are available for rectal compared to colon cancer including radiation treatment. Second, the introduction of total mesorectal excision (TME) has resulted in a tremendous improvement of outcomes in rectal cancer patients. Whether or not a complete mesocolic resection will lead to similar improvements in colon cancer patients has still to be shown. ${ }^{36}$ Nonetheless, both surgery to the primary tumor as well as radiation treatment are local treatment modalities and it is questionable whether they impact overall and cancer-specific survival in the setting of metastatic disease.

Finally, overall and cancer-specific survival are highly influenced by patient's age. Golan et al. showed that the prognosis of patients with metastatic colorectal cancer significantly improved over the last years while this results was mainly limited to patients age 70 and younger. ${ }^{5}$ This finding is important as those are the patients mainly represented in randomized controlled trials as they more likely qualify for aggressive surgical treatment and combination chemoimmunotherapy. ${ }^{37}$ Based on those findings, we further tested whether racial disparity between Whites and Blacks did improve in the subgroup of younger patients ( $\leq 65$ years). However, there was no change in survival difference between Whites and Blacks over time in regard to overall and cancerspecific survival in this subgroup of patients in our study.

We would like to acknowledge the inherent limitations of this study. The main drawback of this analysis is the lack of information on chemotherapeutic drugs or antibodies used, data that cannot be ascertained in the SEER registry. Similarly, information about comorbidities, performance status, and information on site of metastases are not available in the SEER database. Second, for certain parameters (e.g., nodal status, Tstage), there are a large number of missing values. While we did include unknown nodal status as a separate group to the multivariable analyses, we decided to avoid the inclusion of Tstage. Despite these limitations, the present study has a variety of strengths. First, the population-based nature of the registry mirrors the real-world outcomes for White and Black patients with metastatic colorectal cancer and is associated with a high degree of generalizability. It is critically important to assess disparity trends and to which extent advances in often highly selected patients in randomized controlled trials have translated into the overall patient population. Secondly, our study reports data on a 21-year time period. Finally, the large sample size in this study results is associated with a high degree of power.

In conclusion, the results and new treatment strategies assessed by randomized controlled trials have translated to significant improvements in OS and CSS over 21 years in a large cohort of both White and Black patients with metastatic colorectal cancer. However, the discrepancy between overall survival for White and Black patients did not improve over this time period while it slightly decreased for cancer-specific survival. Further efforts are necessary to understand and correct these health care related disparities affecting minorities.

\section{References}

1. Siegel R, Naishadham D, Jemal A. Cancer statistics, 2013. CA: a cancer journal for clinicians 2013;63:11-30.

2. Nordlinger B, Sorbye H, Glimelius B, Poston GJ, Schlag PM, Rougier P, Bechstein WO, Primrose JN, Walpole ET, Finch-Jones M, Jaeck D, Mirza D, Parks RW, Collette L, Praet M, Bethe U, Van Cutsem E, Scheithauer W, Gruenberger T, Group EG-ITC, Cancer Research UK, Arbeitsgruppe Lebermetastasen und-tumoren in der Chirurgischen Arbeitsgemeinschaft O, Australasian Gastro-Intestinal 
Trials G, Federation Francophone de Cancerologie D. Perioperative chemotherapy with FOLFOX4 and surgery versus surgery alone for resectable liver metastases from colorectal cancer (EORTC Intergroup trial 40983): a randomised controlled trial. Lancet 2008;371:1007-1016.

3. Van Cutsem E, Kohne CH, Hitre E, Zaluski J, Chang Chien CR, Makhson A, D'Haens G, Pinter T, Lim R, Bodoky G, Roh JK, Folprecht G, Ruff P, Stroh C, Tejpar S, Schlichting M, Nippgen J, Rougier P. Cetuximab and chemotherapy as initial treatment for metastatic colorectal cancer. The New England journal of medicine 2009;360:1408-1417.

4. Hurwitz H, Fehrenbacher L, Novotny W, Cartwright T, Hainsworth J, Heim W, Berlin J, Baron A, Griffing S, Holmgren E, Ferrara N, Fyfe G, Rogers B, Ross R, Kabbinavar F. Bevacizumab plus irinotecan, fluorouracil, and leucovorin for metastatic colorectal cancer. The New England journal of medicine 2004;350:2335-2342.

5. Golan T, Urban D, Berger R, Lawrence YR. Changing prognosis of metastatic colorectal adenocarcinoma: Differential improvement by age and tumor location. Cancer 2013;119:3084-3091.

6. Robbins AS, Siegel RL, Jemal A. Racial disparities in stage-specific colorectal cancer mortality rates from 1985 to 2008. J Clin Oncol 2012;30:401-405.

7. Halpern MT, Ward EM, Pavluck AL, Schrag NM, Bian J, Chen AY. Association of insurance status and ethnicity with cancer stage at diagnosis for 12 cancer sites: a retrospective analysis. The lancet oncology 2008;9:222-231.

8. Shavers VL, Brown ML. Racial and ethnic disparities in the receipt of cancer treatment. Journal of the National Cancer Institute 2002;94: 334-357.

9. Obeidat NA, Pradel FG, Zuckerman IH, Trovato JA, Palumbo FB, DeLisle S, Mullins CD. Racial/ethnic and age disparities in chemotherapy selection for colorectal cancer. The American journal of managed care 2010;16:515-522.

10. White A, Liu CC, Xia R, Burau K, Cormier J, Chan W, Du XL. Racial disparities and treatment trends in a large cohort of elderly African Americans and Caucasians with colorectal cancer, 1991 to 2002. Cancer 2008;113:3400-3409.

11. Breslin TM, Morris AM, Gu N, Wong SL, Finlayson EV, Banerjee M, Birkmeyer JD. Hospital factors and racial disparities in mortality after surgery for breast and colon cancer. J Clin Oncol 2009;27:39453950.

12. Berry J, Caplan L, Davis S, Minor P, Counts-Spriggs M, Glover R, Ogunlade V, Bumpers K, Kauh J, Brawley OW, Flowers C. A blackwhite comparison of the quality of stage-specific colon cancer treatment. Cancer 2010;116:713-722.

13. Zhang W, Ayanian JZ, Zaslavsky AM. Patient characteristics and hospital quality for colorectal cancer surgery. International journal for quality in health care: journal of the International Society for Quality in Health Care / ISQua 2007;19:11-20.

14. The National Academies. Available at: http://www 7. nationalacademies.org/ocga/laws/PL106_525.asp. Last accessed 8 Nov 2013

15. SEER. National Cancer Institute, Surveillance Epidemiology and End Results. Available at: http://seer.cancer.gov/. Last accessed 8 Nov 2013

16. Weiser MR, Gonen M, Chou JF, Kattan MW, Schrag D. Predicting survival after curative colectomy for cancer: individualizing colon cancer staging. J Clin Oncol 2011;29:4796-4802.

17. Fine JP, Gray RJ. A proportional hazards model for the subdistribution of a competing risk. Journal of the American Statistical Association 1999;94:496-509.

18. de Haas RJ, Wicherts DA, Andreani P, Pascal G, Saliba F, Ichai P, Adam R, Castaing D, Azoulay D. Impact of expanding criteria for resectability of colorectal metastases on short- and long-term outcomes after hepatic resection. Annals of surgery 2011;253:10691079.
19. Wicherts DA, Miller R, de Haas RJ, Bitsakou G, Vibert E, Veilhan LA, Azoulay D, Bismuth H, Castaing D, Adam R. Long-term results of two-stage hepatectomy for irresectable colorectal cancer liver metastases. Annals of surgery 2008;248:994-1005.

20. Adam R. Developing strategies for liver metastases from colorectal cancer. Seminars in oncology 2007;34:S7-11.

21. Onaitis MW, Petersen RP, Haney JC, Saltz L, Park B, Flores R, Rizk N, Bains MS, Dycoco J, D'Amico TA, Harpole DH, Kemeny N, Rusch VW, Downey R. Prognostic factors for recurrence after pulmonary resection of colorectal cancer metastases. The Annals of thoracic surgery 2009;87:1684-1688.

22. Lam VW, Laurence JM, Pang T, Johnston E, Hollands MJ, Pleass HC, Richardson AJ. A systematic review of a liver-first approach in patients with colorectal cancer and synchronous colorectal liver metastases. HPB: the official journal of the International Hepato Pancreato Biliary Association 2013;

23. Douillard JY, Siena S, Cassidy J, Tabernero J, Burkes R, Barugel M, Humblet Y, Bodoky G, Cunningham D, Jassem J, Rivera F, Kocakova I, Ruff P, Blasinska-Morawiec M, Smakal M, Canon JL, Rother M, Oliner KS, Wolf M, Gansert J. Randomized, phase III trial of panitumumab with infusional fluorouracil, leucovorin, and oxaliplatin (FOLFOX4) versus FOLFOX4 alone as first-line treatment in patients with previously untreated metastatic colorectal cancer: the PRIME study. J Clin Oncol 2010;28:4697-4705.

24. Grothey A, Van Cutsem E, Sobrero A, Siena S, Falcone A, Ychou M, Humblet Y, Bouche O, Mineur L, Barone C, Adenis A, Tabernero J, Yoshino T, Lenz HJ, Goldberg RM, Sargent DJ, Cihon F, Cupit L, Wagner A, Laurent D, Group CS. Regorafenib monotherapy for previously treated metastatic colorectal cancer (CORRECT): an international, multicentre, randomised, placebo-controlled, phase 3 trial. Lancet 2013;381:303-312.

25. Van Cutsem E, Tabernero J, Lakomy R, Prenen H, Prausova J, Macarulla T, Ruff P, van Hazel GA, Moiseyenko V, Ferry D, McKendrick J, Polikoff J, Tellier A, Castan R, Allegra C. Addition of aflibercept to fluorouracil, leucovorin, and irinotecan improves survival in a phase III randomized trial in patients with metastatic colorectal cancer previously treated with an oxaliplatin-based regimen. J Clin Oncol 2012;30:3499-3506.

26. Bennouna J, Sastre J, Arnold D, Osterlund P, Greil R, Van Cutsem E, von Moos R, Vieitez JM, Bouche O, Borg C, Steffens CC, AlonsoOrduna V, Schlichting C, Reyes-Rivera I, Bendahmane B, Andre T, Kubicka S, Investigators MLS. Continuation of bevacizumab after first progression in metastatic colorectal cancer (ML18147): a randomised phase 3 trial. The lancet oncology 2013;14:29-37.

27. Swan J, Breen N, Coates RJ, Rimer BK, Lee NC. Progress in cancer screening practices in the United States: results from the 2000 National Health Interview Survey. Cancer 2003;97:1528-1540.

28. James TM, Greiner KA, Ellerbeck EF, Feng C, Ahluwalia JS. Disparities in colorectal cancer screening: a guideline-based analysis of adherence. Ethnicity \& disease 2006;16:228-233.

29. Meissner HI, Breen N, Klabunde CN, Vernon SW. Patterns of colorectal cancer screening uptake among men and women in the United States. Cancer Epidemiol Biomarkers Prev 2006; 15:389-394.

30. Musa D, Schulz R, Harris R, Silverman M, Thomas SB. Trust in the health care system and the use of preventive health services by older black and white adults. American journal of public health 2009;99: 1293-1299.

31. Kennedy BR, Mathis CC, Woods AK. African Americans and their distrust of the health care system: healthcare for diverse populations. Journal of cultural diversity 2007;14:56-60.

32. Meyerhardt JA, Niedzwiecki D, Hollis D, Saltz LB, Hu FB, Mayer RJ, Nelson H, Whittom R, Hantel A, Thomas J, Fuchs CS. Association of dietary patterns with cancer recurrence and survival in patients with stage III colon cancer. JAMA: the journal of the American Medical Association 2007;298:754-764. 
33. Meyerhardt JA, Giovannucci EL, Holmes MD, Chan AT, Chan JA, Colditz GA, Fuchs CS. Physical activity and survival after colorectal cancer diagnosis. J Clin Oncol 2006;24:3527-3534.

34. Campbell PT, Patel AV, Newton CC, Jacobs EJ, Gapstur SM. Associations of recreational physical activity and leisure time spent sitting with colorectal cancer survival. J Clin Oncol 2013;31:876885.

35. Laiyemo AO, Doubeni C, Pinsky PF, Doria-Rose VP, Bresalier R, Lamerato LE, Crawford ED, Kvale P, Fouad M, Hickey T, Riley T, Weissfeld J, Schoen RE, Marcus PM, Prorok PC, Berg CD. Race and colorectal cancer disparities: health-care utilization vs different cancer susceptibilities. Journal of the National Cancer Institute 2010;102:538-546

36. West NP, Hohenberger W, Weber K, Perrakis A, Finan PJ, Quirke P. Complete mesocolic excision with central vascular ligation produces an oncologically superior specimen compared with standard surgery for carcinoma of the colon. J Clin Oncol 2010;28:272-278.

37. Mohile SG, Hardt M, Tew W, Owusu C, Klepin H, Gross C, Gajra A, Lichtman SM, Feng T, Togawa K, Ramani R, Katheria V, Hansen K, Hurria A, Cancer, Aging Research G. Toxicity of bevacizumab in combination with chemotherapy in older patients. The oncologist 2013;18:408-414. 